\title{
Effect of Electron Irradiation on the Thermodynamical and Optical Properties of Cholesteryl Pelargonate
}

\author{
Rohit Verma ${ }^{\mathrm{a}, \mathrm{b}}$, R. Dhar ${ }^{\mathrm{b}, *}$, R. Dabrowski ${ }^{\mathrm{a}, \mathrm{c}}$, M. C. Rath ${ }^{\mathrm{d}}$ and S. K. Sarkar ${ }^{\mathrm{d}}$ \\ ${ }^{a}$ Physics Department, University of Allahabad, Allahabad, India \\ ${ }^{b}$ Centre of Material Sciences, Institute of Interdisciplinary Studies (IIDS), University of Allahabad, Allahabad, India \\ ${ }^{c}$ Institute of Chemistry, Military University of Technology, Warsaw, Poland \\ ${ }^{d}$ Radiation \& Photochemistry Division, Bhabha Atomic Research Centre, Trombay, Mumbai-400085, India
}

\begin{abstract}
Thermodynamical and optical properties of pure and electron beam irradiated (20,80 and $100 \mathrm{kGy}$ doses) liquid crystalline material cholesteryl pelargonate (nonanoate) have been investigated by differential scanning calorimeter, polarized light microscopy and ultraviolet-visible spectroscopy. Transition temperatures, enthalpies and entropies are found to be lowered due to the irradiation. A donor-acceptor type charge transfer complex peak is observed besides the pure sample peak in the ultraviolet-visible spectra due to irradiation. The concentrations of impurities have been estimated by the area of the pure and charge transfer complex peaks besides using the Van't Hoff equation. The concentration of impurity is found to increase linearly with the irradiation dose.
\end{abstract}

Keywords: Electron beam irradiation, Differential Scanning Calorimeter, UV-Vis spectroscopy, Charge transfer complex, Van't Hoff Equation.

\section{INTRODUCTION}

Liquid crystalline materials have been useful for display devices (watches, calculators, automobile dashboards, televisions, multi media projectors etc.) as well as in electro tunable lasers, optical fibers and lenses, liquid crystal colloids, organic charge transport devices, light modulators, electrically controllable optical shutters, artificial muscles, drug delivery systems and many others since their discovery in 1888 [1]. They are the backbone of present high-tech electronic systems. The devices made up of liquid crystalline materials are some times used in radiation prone areas such as nuclear installation centers and space applications. $\mathrm{Nu}$ clear reactors, war fields and space radiation are the major sources of radiation. When these devices are used in such an environment, occasionally for a long time, different types and doses of radiation may cause their malfunctioning. The molecules of liquid crystalline materials are highly anisotropic. When a high energy particle passes through a substance the loss of energy taking place is a complex series of momentum sharing events (collisions) with the energy dividing itself into many small packets, some of which are dissipated as heat whereas others are stored as damage. In the case of a massive particle, such as a proton, neutron or a heavy ion, a spike of atomic displacements stores energy as terminal subclusters nanoseconds after the particle has passed through the solid $[2,3]$. Therefore, it becomes important to study in which way different types and doses of radiation affect these materials. The study of the electrical

*Address correspondence to this author at the Centre of Material Sciences, Institute of Interdisciplinary Studies (IIDS), University of Allahabad, Allahabad, India; Tel: +919415278539; Fax: +915322460017;

E-mail: dr_ravindra_dhar@hotmail.com and thermodynamical properties of cholesteryl myristate $(\mathrm{ChM})$ shows that the various transition temperatures, enthalpies and entropies are decreased while the electrical conductivity is increased due to $\gamma$-irradiation [4]. Proton and $\gamma$ irradiation of different doses also drastically change the properties of several esters of cholesterol [5]. In some of our earlier work, we have found that the different display parameters of basic liquid crystalline materials $(5 \mathrm{CB}, 8 \mathrm{CB}$ and $6 \mathrm{CHBT}$ ) can be optimized by certain doses of electron irradiation [6-8].

Cholesteryl pelargonate $(\mathrm{ChP})$ is $9^{\text {th }}$ member (nonanoate) of the cholesteryl ester series and it is the first shortest chain length member of this series, which possesses a monotropic smectic $(\mathrm{SmA})$ phase with chiral nematic or cholesteric $\left(\mathrm{N}^{*}\right)$ and blue phases in the cooling cycle $[9,10]$. In the present work, we have irradiated $\mathrm{ChP}$ by an electron beam of $7 \mathrm{MeV}$ up to a dose of $100 \mathrm{kGy}$ and have investigated the changes in the thermodynamical and optical properties. The structure of the $\mathrm{ChP}$ is given as follows.

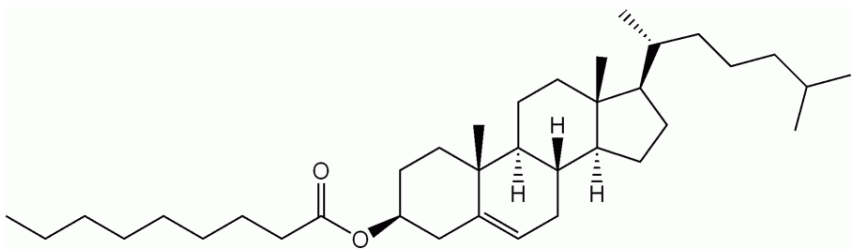

Molecular structure of cholesteryl pelargonate (nonanoate)

\section{EXPERIMENTAL TECHNIQUES}

The irradiation experiments were performed by an electron beam of $7 \mathrm{MeV}$ energy and pulse duration of $3 \mu \mathrm{s}$ by a LINAC setup at Bhabha Atomic Research Center (BARC) 
[11], Mumbai, India and at the National Center for Free Radical Research, University of Pune, Pune, India. UV-VIS spectra were acquired on an Ocean Optics' UV-VIS spectrophotometer DH-2000 coupled with an HR-4000-CG-UVNIR detector. For acquiring the spectra, pure and irradiated materials were dissolved in chloroform and placed into a quartz spectro cell of $1 \mathrm{~mm}$ path length. For peak conformation different scans were acquired repeatedly. Thermodynamical studies of the pure and irradiated samples were carried out on a Perkin Elmer differential scanning calorimeter DSC-7. For the thermodynamical study $2-3 \mathrm{mg}$ of the sample is needed which is weighed on an electro balance from Cahn (Model C-33) having an accuracy of $1 \mu \mathrm{g}$ and crimped in aluminum pans. The crimped pan is kept in one sample holder of the DSC while an identical pan is kept in the other reference holder as a reference pan. To purge any impurity around the sample in the sample holder, nitrogen gas is flown at about $25-30 \mathrm{lb} / \mathrm{inch}^{2}$ pressure. DSC is allowed to run initially for first five cycles with a scan rate of $5^{\circ} \mathrm{C} / \mathrm{min}$ in the range of $30-99{ }^{\circ} \mathrm{C}$ in order to stabilize the transition temperatures and enthalpy of the transitions. Peak transition temperatures (Tp) which are considered as phase transition temperatures have been determined with the accuracy of 0.1
$\mathrm{K}$ whereas transition enthalpies $(\Delta \mathrm{H})$ have been determined with an accuracy better than $5 \%$ for fully-grown peaks. However, for weak peaks, uncertainties are large. DSC has been calibrated using zinc and indium at a scanning rate of $10 \mathrm{~K} / \mathrm{min}$. Different mesophases of the pure and irradiated samples have been identified from a texture study with the help of a CENSICO made polarized light microscope (PLM). The textures were acquired on a computer by a CCTV camera (model MINTRON). Temperature of the samples kept between two cover slips of glass under the microscope has been controlled with the help of a hot stage of Instec with temperature resolution of $3 \mathrm{mK}$ and temperature accuracy of $0.1{ }^{\circ} \mathrm{C}$. Other experimental details are described in our earlier publications $[12,13]$.

\section{RESULTS AND DISCUSSION}

The typical DSC thermograms showing the variations of the heat flow $(\mathrm{mW})$ with temperature $\left({ }^{\circ} \mathrm{C}\right)$ at a scan rate of 5 ${ }^{\circ} \mathrm{C} / \mathrm{min}$ in the heating and cooling cycles are shown in Fig. (1) for the pure and irradiated samples. From Fig. (1) (a), we see that in the heating cycle only crystal-cholesteric $\left(\mathrm{Cr}-\mathrm{N}^{*}\right)$ and cholesteric-isotropic $\left(\mathrm{N}^{*}-\mathrm{I}\right)$ transitions are observed whereas Fig. (1) (b) shows that in the cooling cycle, the ob-

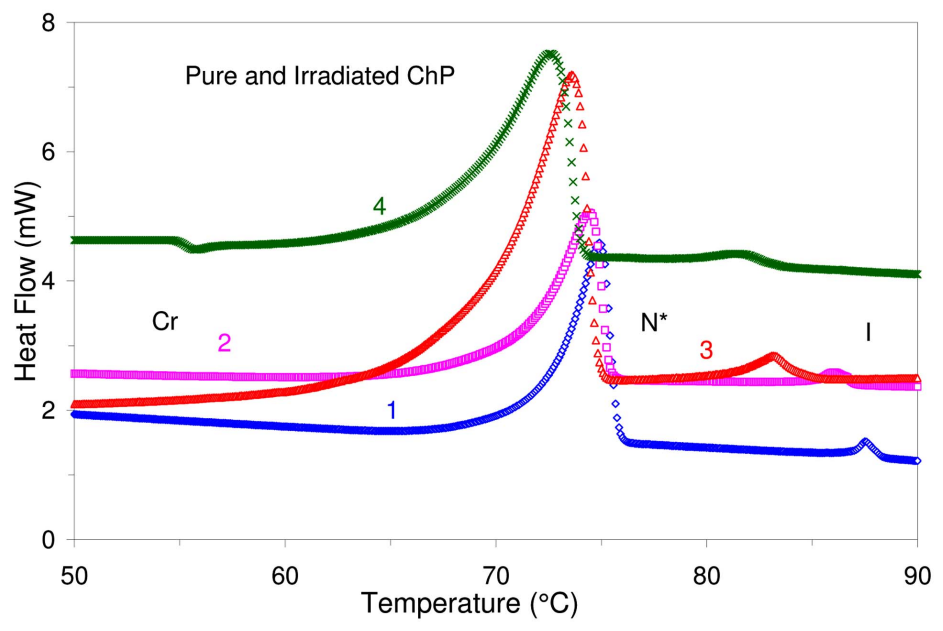

(a)

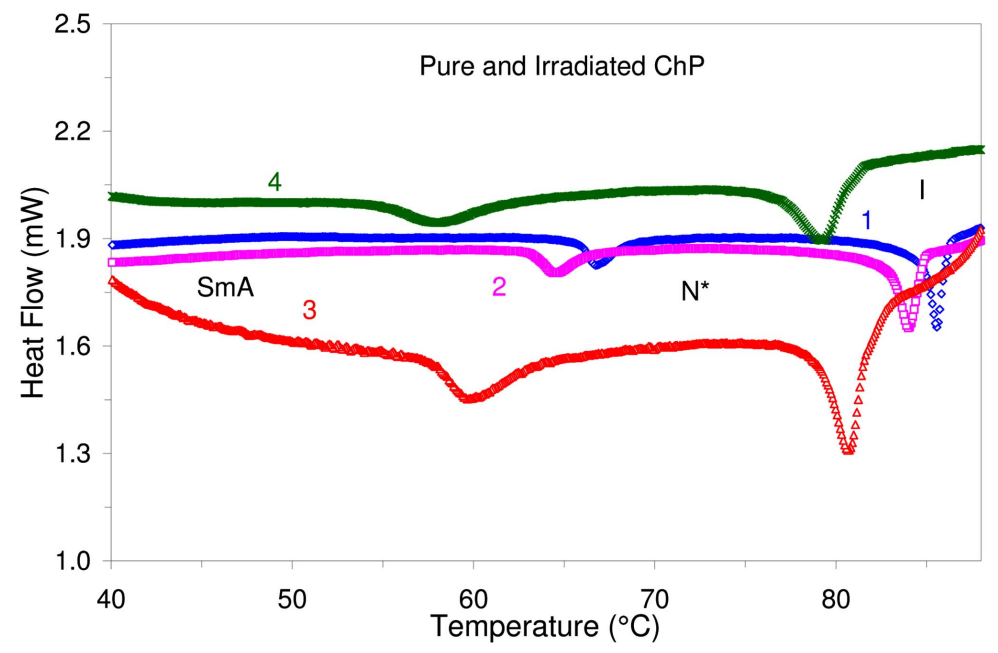

(b)

Fig. (1). Variation of heat flow $(\mathrm{mW})$ with temperature $\left({ }^{\circ} \mathrm{C}\right)$ at a scan rate of $5{ }^{\circ} \mathrm{C} / \mathrm{min}$ in the (a) heating and (b) cooling cycle of $(1)$ pure ChP, (2) irradiated ChP (20 kGy), (3) irradiated ChP (80 kGy) and (4) irradiated ChP (100 kGy). 
served transitions are isotropic-cholestric $\left(\mathrm{I}-\mathrm{N}^{*}\right)$ and cholestric-smectic A $\left(\mathrm{N}^{*}-\mathrm{SmA}\right)$. The $\mathrm{SmA}-\mathrm{Cr}$ transition is not observed in the cooling cycle in any of the samples because the analyzer of the DSC looses its control below $45^{\circ} \mathrm{C}$ and the complete crystal phase is observed only after overnight cooling.

The identification of the particular mesophases was done by a texture study. Plates $\mathbf{1}$ and $\mathbf{2}$ show the textures of the unaligned pure and $80 \mathrm{kGy}$ irradiated samples in the $\mathrm{N}^{*}$ phase at $72.5^{\circ} \mathrm{C}$. Similarly Plates $\mathbf{3}$ and $\mathbf{4}$ show the textures of the unaligned pure and $80 \mathrm{kGy}$ irradiated samples in the SmA phase at $64.4{ }^{\circ} \mathrm{C}$ and $64.1{ }^{\circ} \mathrm{C}$, respectively. From the texture study, we find that pure $\mathrm{ChP}$ crystallizes at $41.7^{\circ} \mathrm{C}$, while $\mathrm{ChP}(80 \mathrm{kGy})$ crystallizes at $35.2^{\circ} \mathrm{C}$.

The phase transition temperatures increase linearly with the increasing scan rate [14-16]. Fig. (2) (a-d) show how the

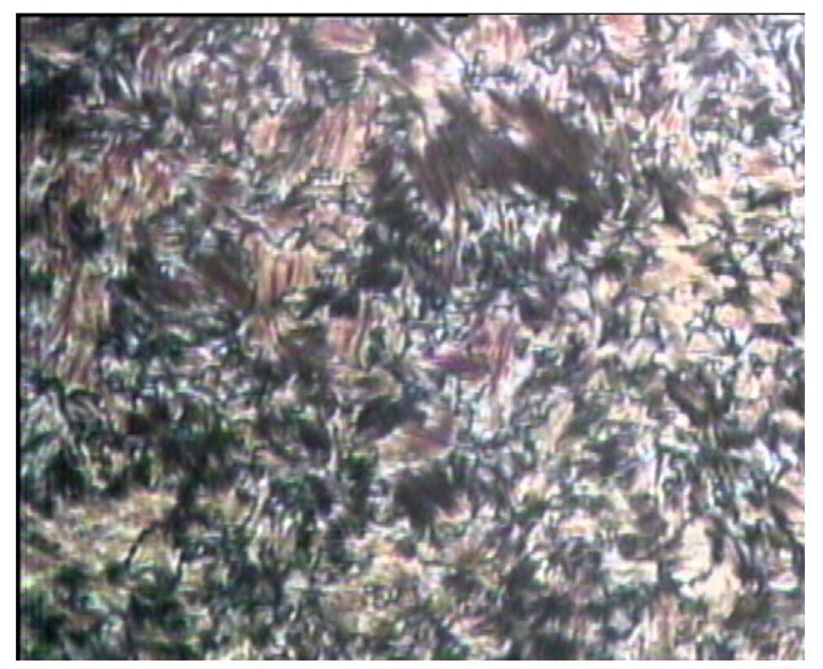

Plate-1

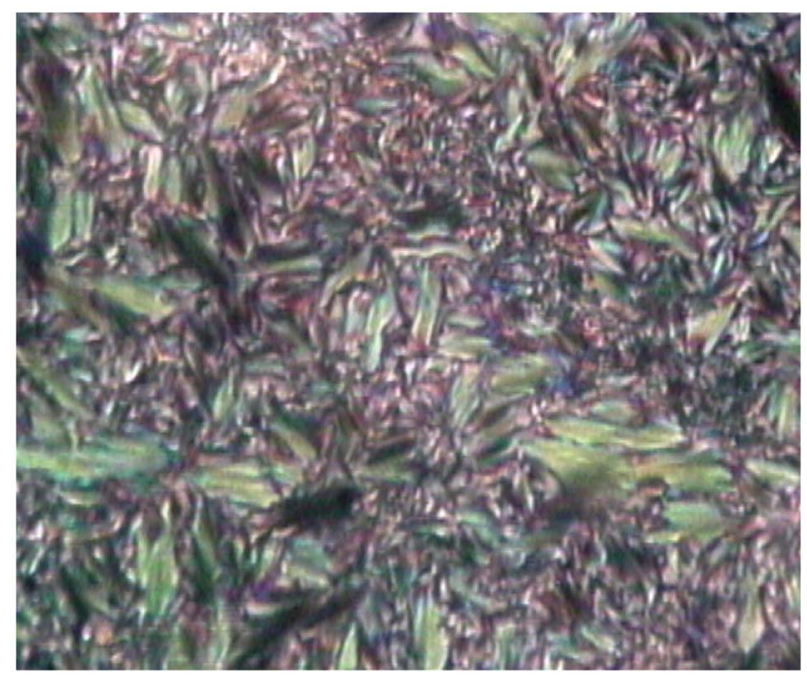

Plate-3 transition temperatures of different mesophases of the pure and irradiated $\mathrm{ChP}$ vary with the scan rate. In this plot, we have taken DSC observations of the pure and irradiated samples with different scan rates from 2.5 to $10{ }^{\circ} \mathrm{C} / \mathrm{min}$ at an interval of 2.5 and using a least square fit have extrapolated the graph to $0{ }^{\circ} \mathrm{C} / \mathrm{min}$. The extrapolated transition temperatures at the virtual scan rate of $0{ }^{\circ} \mathrm{C} / \mathrm{min}$ are listed in Table $\mathbf{1}$ for various doses of irradiation. This table shows that the transition temperatures of the different mesophases are depressed with the increasing irradiation dose.

Normally the mixing of any impurity in a compound depresses the transition temperatures of the material [16]. Alfassi et al. have found that the color transition temperatures of cholesteryl esters are lowered due to $\gamma$-irradiation and that lowering in the transition temperature depends upon the absorbed dose of irradiation [17]. In our case all the transition

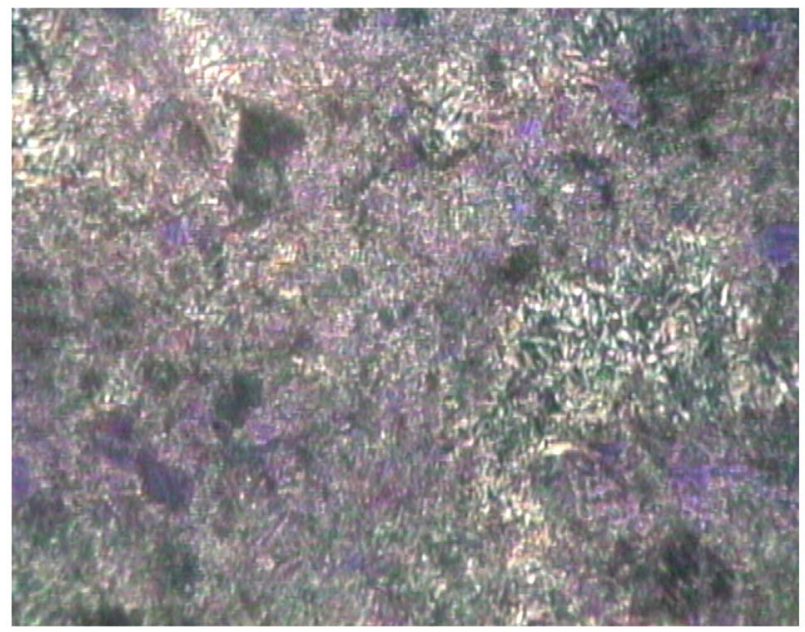

Plate-2

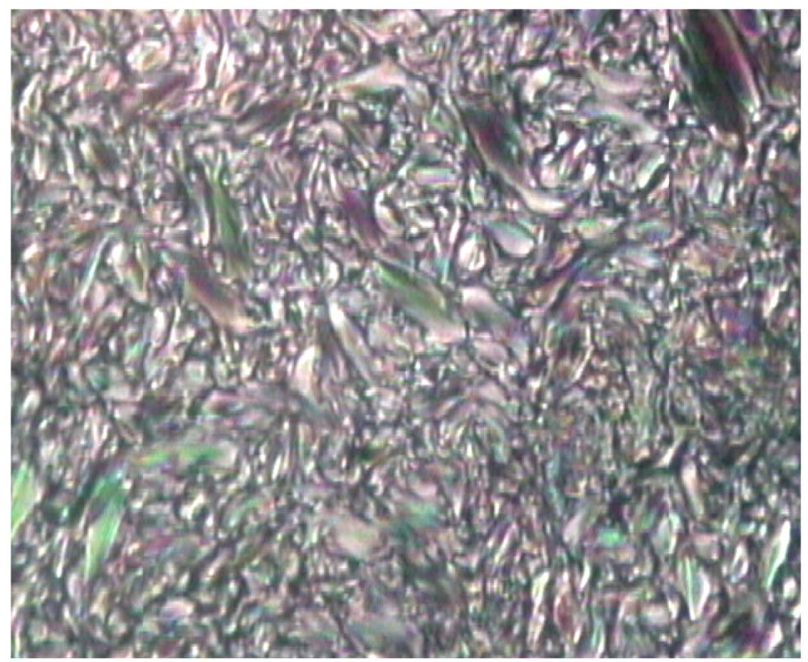

Plate-4

Plate 1-4. Plate 1 and 2 show the textures of the unaligned pure and $80 \mathrm{kGy}$ irradiated sample in the $\mathrm{N}^{*}$ phase at $72.5^{\circ} \mathrm{C}$ respectively. Plate 3 and 4 show the textures of the unaligned pure and $80 \mathrm{kGy}$ irradiated sample in the SmA phase at $64.4^{\circ} \mathrm{C}$ and $64.1^{\circ} \mathrm{C}$ respectively. 


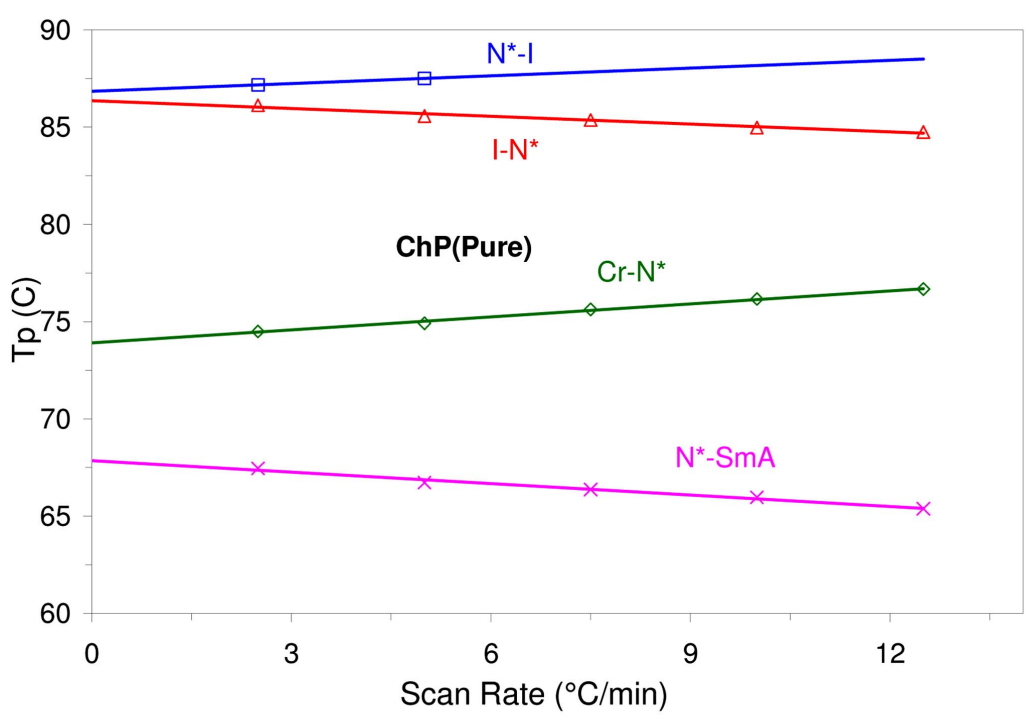

2(a)

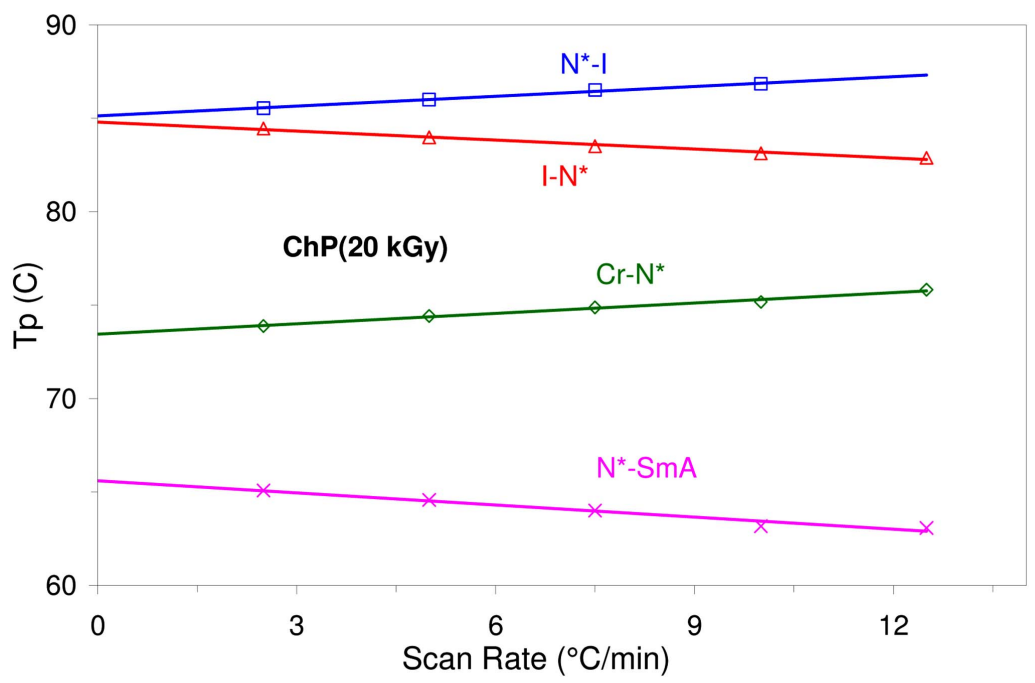

2(b)

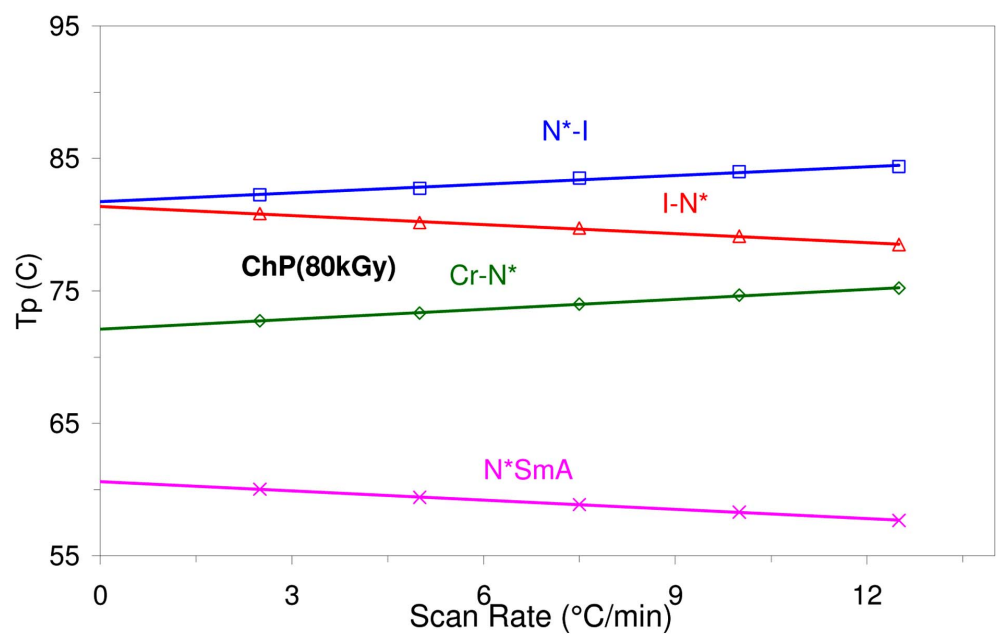


Fig. (2). Contd....

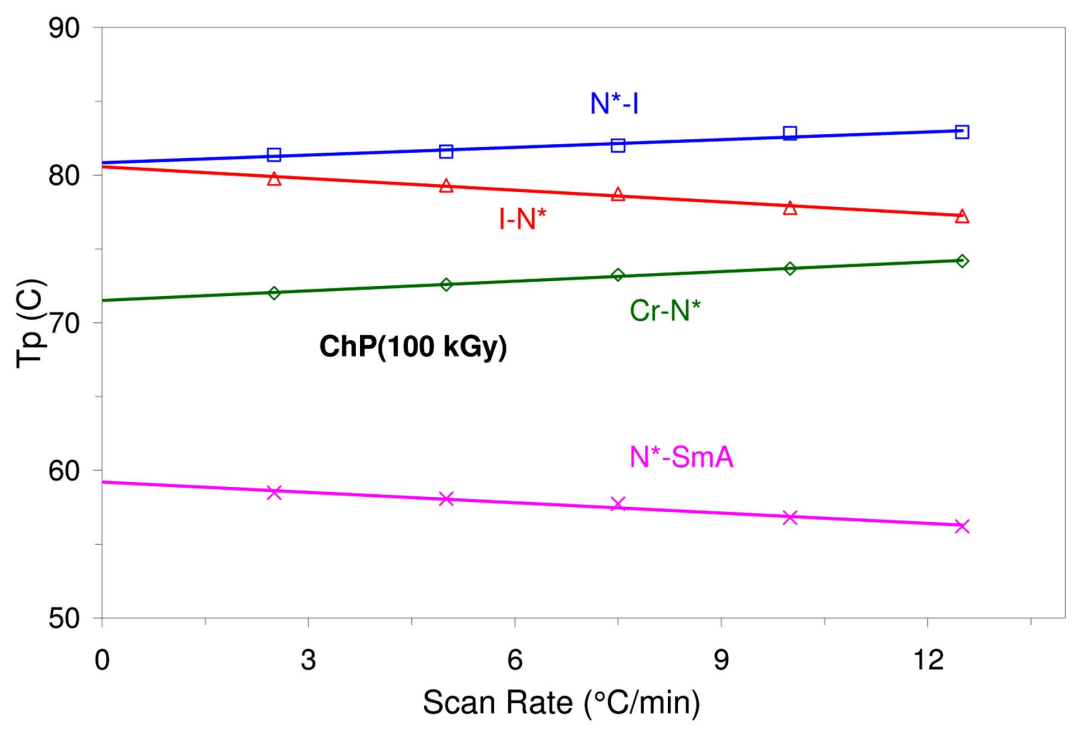

2(d)

Fig. (2). Variation of transition temperature (in ${ }^{\circ} \mathrm{C}$ ) with different scan rates (in ${ }^{\circ} \mathrm{C} / \mathrm{min}$ ) of the different transitions, (a) pure $\mathrm{ChP},(\mathbf{b})$ irradiated $\mathrm{ChP}(20 \mathrm{kGy})$, (c) irradiated $\mathrm{ChP}(80 \mathrm{kGy})$ and (d) irradiated $\mathrm{ChP}(100 \mathrm{kGy})$. Lines having positive slopes represent heating cycles whereas the lines with negative slopes represent cooling cycles.

Table 1. Variation of Transition Temperatures (in ${ }^{\circ} \mathrm{C}$ ) at the Extrapolated Scan Rate of $0{ }^{\circ} \mathrm{C} / \mathrm{min}$, Average Transition Enthalpies (in $\mathrm{kCal} / \mathrm{mol}$ ), Average Transition Entropies (in Cal/mol-K) with Varying Irradiation Dose

\begin{tabular}{|c|c|c|c|c|}
\hline \multicolumn{5}{|c|}{ Transition Temperatures $\left(\right.$ in ${ }^{\circ} \mathrm{C}$ ) } \\
\hline Dose (kGy) & $\mathrm{Cr}-\mathrm{N}^{*}$ & $\mathrm{~N}^{*}-\mathrm{I}$ & $\mathrm{I}-\mathrm{N}^{*}$ & $\mathrm{~N}^{*}-\mathrm{SmA}$ \\
\hline 0 & 73.9 & 86.8 & 86.4 & 67.9 \\
\hline 80 & 72.1 & 81.7 & 81.4 & 60.6 \\
\hline 100 & 71.5 & 81.1 & 80.3 & 58.9 \\
\hline Dose (kGy) & $\mathrm{Cr}-\mathrm{N}^{*}$ & $\mathrm{~N}^{*}-\mathrm{I}$ & $\mathrm{I}-\mathrm{N}^{*}$ & $\mathrm{~N}^{*}-\mathrm{SmA}$ \\
\hline 0 & 4.90 & 0.148 & 0.204 & 0.086 \\
\hline 20 & 4.62 & 0.145 & 0.162 & 0.079 \\
\hline 80 & 4.11 & 0.138 & 0.157 & 0.072 \\
\hline 0 & 14.1 & 0.411 & 0.570 & 0.252 \\
\hline 20 & 13.3 & 0.402 & 0.453 & 0.234 \\
\hline 80 & 11.9 & 0.389 & 0.446 & 0.216 \\
\hline 100 & 10.1 & 0.367 & 0.442 & 0.214 \\
\hline
\end{tabular}

temperatures of the different mesophases are also decreasing with the increasing dose. Variation of the transition temperatures of different mesophases with the increasing irradiation dose is shown in Fig. (3). These values of the different transi- tion temperatures of the pure sample agree well with literature data $[18,19]$. Comparison of the transition temperatures of the pure and irradiated materials show that $\mathrm{Cr}-\mathrm{N}^{*}, \mathrm{~N}^{*}-\mathrm{I}$, $\mathrm{I}-\mathrm{N}^{*}$, and $\mathrm{N}^{*}-\mathrm{SmA}$ transition temperature are depressed by 


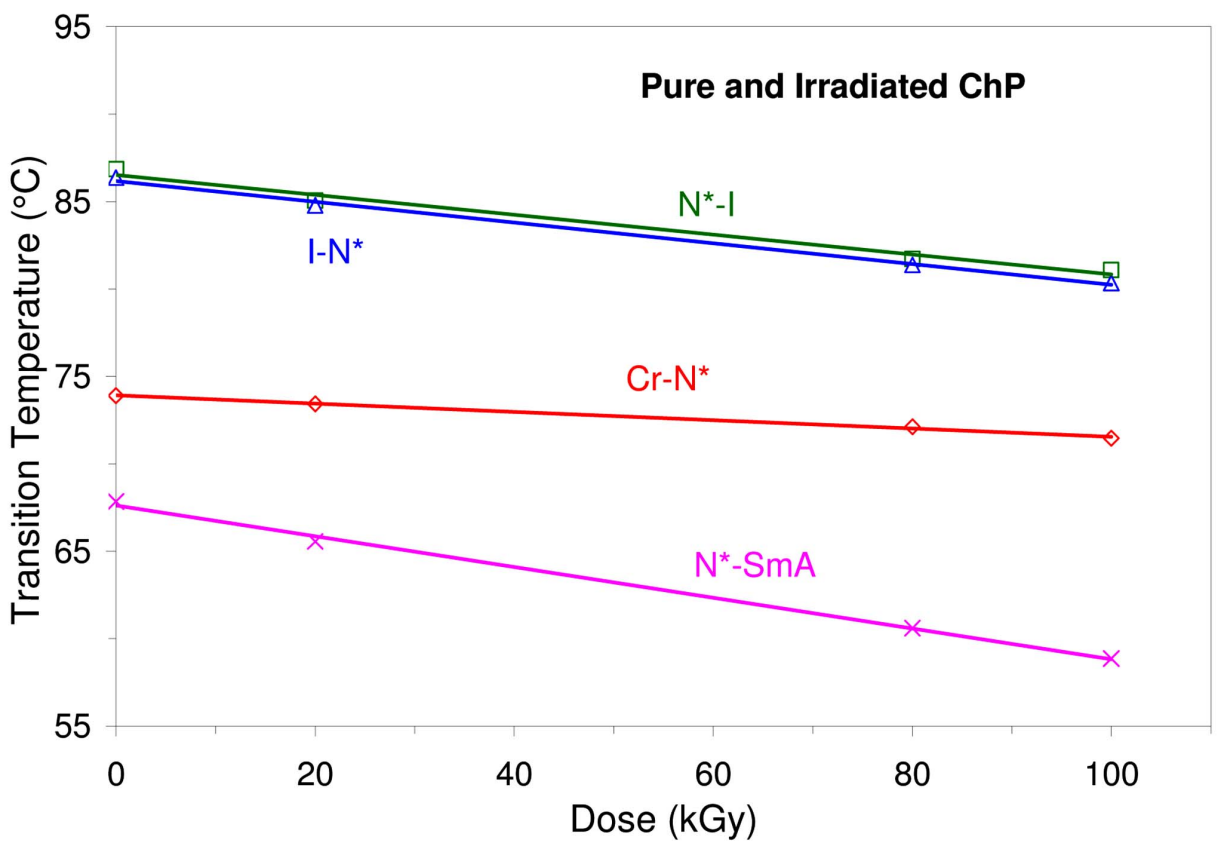

Fig. (3). Variation of the transition temperature (in ${ }^{\circ} \mathrm{C}$ ) with the irradiation dose (in kGy).

$2.4{ }^{\circ} \mathrm{C}, 5.7{ }^{\circ} \mathrm{C}, 6.1{ }^{\circ} \mathrm{C}$ and $9.0^{\circ} \mathrm{C}$, respectively, due to 100 $\mathrm{kGy}$ doses of electron irradiation. In our earlier publication, we have reported that $\gamma$-irradiation of $500 \mathrm{kGy}$ dose produces a depression of $4.0{ }^{\circ} \mathrm{C}$ in the $\mathrm{Cr}-\mathrm{N}^{*}$ transition temperature $\left(\mathrm{T}_{\mathrm{Cr}-\mathrm{N}^{*}}\right)$, of $9.8^{\circ} \mathrm{C}$ in the $\mathrm{N}^{*}-\mathrm{I}-\mathrm{N}^{*}$ transition temperature $\left(\mathrm{T}_{\mathrm{N}^{*}-\mathrm{I}-}\right.$ $\left.\mathrm{N}^{*}\right)$ and of $15.4{ }^{\circ} \mathrm{C}$ in the $\mathrm{N}^{*}-\mathrm{SmA}$ transition temperature $\left(\mathrm{T}_{\mathrm{N}^{*} \text {-SmA }}\right)$ [14]. The above data show that electron beam irradiation is more damaging than $\gamma$-irradiation. However, from the comparison of the data of pure and irradiated materials, we find that in the heating cycle the $\mathrm{N}^{*}$ range decreases by $26 \%$ while in cooling cycle, it increases by $16 \%$ due to electron beam irradiation. From the thermodynamical and optical study, we find that the range of the SmA phase is decreased by $4 \%$.
Variation of the average transition enthalpies $(\Delta H$ in $\mathrm{kCal} / \mathrm{mol}$ ) with irradiation dose is shown in Fig. (4) and Table 1. Transition enthalpies of the different mesophases of the pure ChP are in a good agreement with literature data [18]. Comparison of the transition enthalpies of the different mesophases of the pure and irradiated ChP show that the average transition enthalpies are lowered due to electron beam irradiation. Due to electron irradiation of $100 \mathrm{kGy}$ dose, transition enthalpies of $\mathrm{Cr}-\mathrm{N}^{*}, \mathrm{I}-\mathrm{N}^{*}$ and $\mathrm{N}^{*}-\mathrm{SmA}$ transitions are lowered by $29 \%, 23 \%$ and $8 \%$ respectively. Earlier, it was observed that due to $\gamma$-irradiation of $500 \mathrm{kGy}$ dose on $\mathrm{ChP}, \mathrm{Cr}-\mathrm{N}^{*}, \mathrm{~N}^{*}-\mathrm{I}_{-} \mathrm{N}^{*}$ and $\mathrm{N}^{*}-\mathrm{SmA}$ transition enthalpies are decreased by $27 \%, 23 \%$ and $7 \%$ respectively [ 18 ].

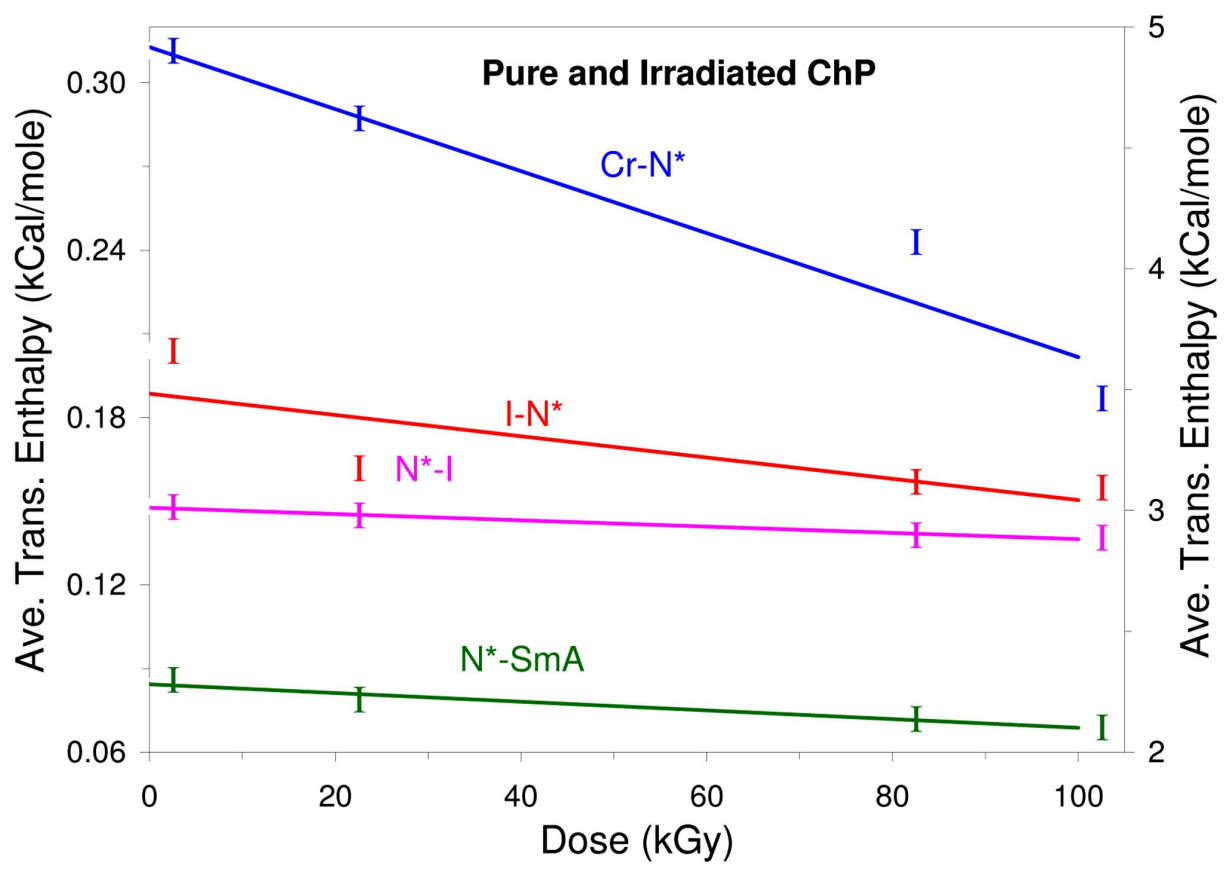

Fig. (4). Variation of the average transition enthalpies $(\Delta \mathrm{H}$, in $\mathrm{kCal} / \mathrm{mole})$ with irradiation dose (in $\mathrm{kGy})$. 
Fig. (5) shows the variation of average transition entropies $(\Delta \mathrm{S}$, in $\mathrm{Cal} / \mathrm{mol}-\mathrm{K})$ with increasing irradiation doses. The transition entropies with varying doses are also listed in Table 1. Comparison of the average transition entropies of the pure and irradiated materials show that $\mathrm{Cr}-\mathrm{N}^{*}, \mathrm{I}^{*} \mathrm{~N}^{*}$ and $\mathrm{N}^{*}$-SmA transition entropies are decreased by $29 \%, 22 \%$ and $15 \%$ respectively due to electron beam irradiation of 100 $\mathrm{kGy}$ dose. As entropy is related with the order of a system and assuming a crystal $(\mathrm{Cr})$ phase as the most ordered phase, it can be said that if the change in entropy while going from $\mathrm{Cr}$ to $\mathrm{N}^{*}$ phase is decreasing then it implies that the order and hence stability of the $\mathrm{N}^{*}$ phase is increasing. The same can be concluded for the SmA phase. From the lowering of transition entropies, it may be concluded that the ordering of the mesophases of $\mathrm{ChP}$ is improving on electron beam irradiation.
The UV-VIS spectra acquired for the pure and irradiated $\mathrm{ChP}$ are shown in Fig. (6). In the case of pure $\mathrm{ChP}$, a single peak is observed at $252.0 \mathrm{~nm}$ from which the band gap of $\mathrm{ChP}$ comes out to be $4.93 \mathrm{eV}$. In an electron irradiated sample an additional peak is observed at $289.2 \mathrm{~nm}$ (corresponding energy $4.30 \mathrm{eV}$ ) along with the pure sample peak. The UV-VIS spectra suggest the possibility of the formation of a donor-accepter type charge transfer (CT) complex [20, 21]. If we compare the area under the two peaks, i.e. peak of the pure sample and that of the CT complex, we can estimate the concentration of the impurities produced by irradiation. Area under the peaks have been determined by two methods (i) by counting small squares $\left(1 \mathrm{~mm}^{2}\right)$ under the area covered by the peaks and (ii) by a weighing method. From both the methods, concentration of impurities come out to be $6 \pm 2 \%$.

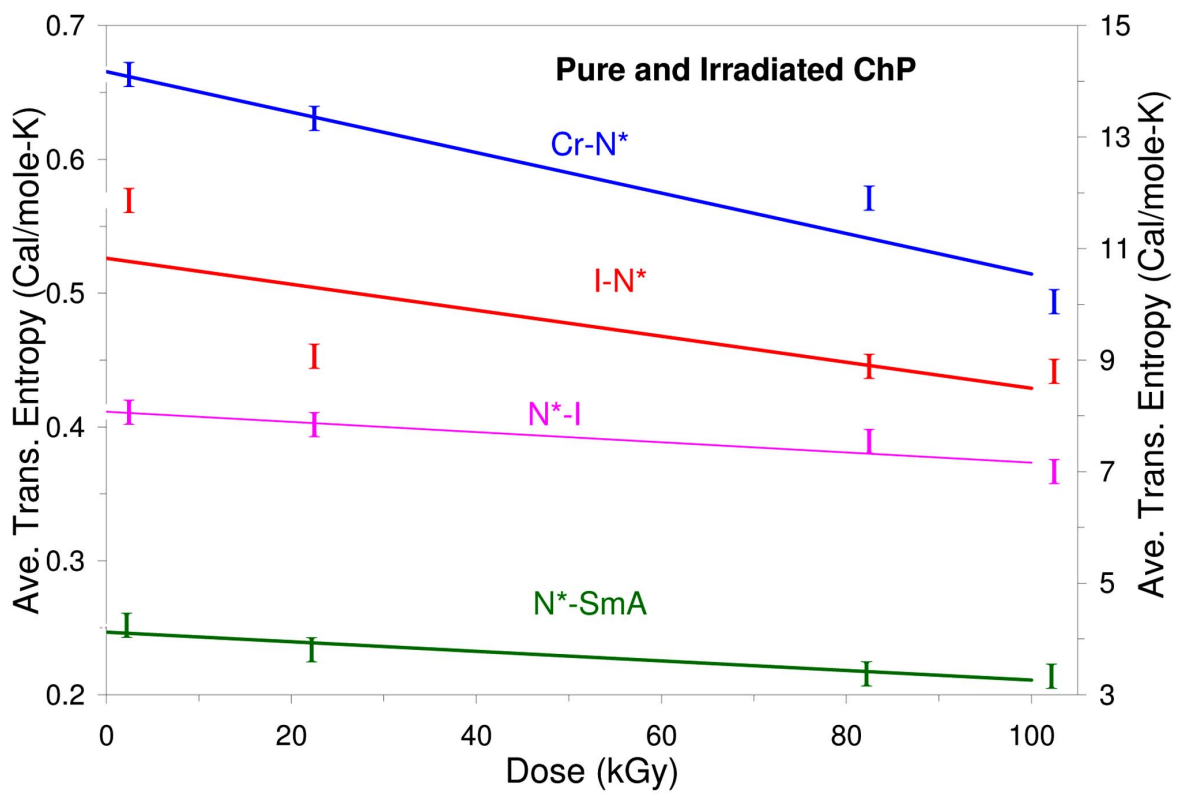

Fig. (5). Variation of the average transition entropies $(\Delta \mathrm{S}$, in $\mathrm{Cal} / \mathrm{mole}-\mathrm{K})$ with irradiation dose (in kGy).

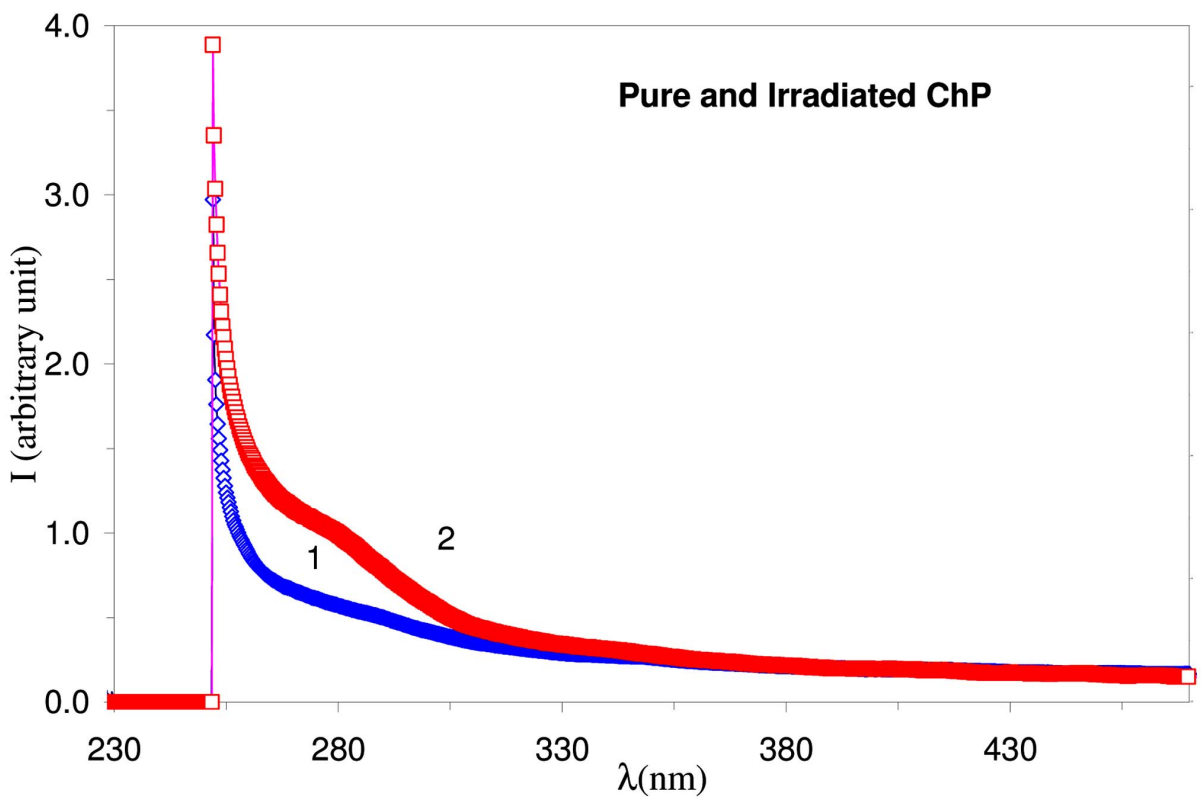

Fig. (6). Variation of the relative intensity with wavelength (nm) for pure and electron irradiated ChP: Curve 1 for pure ChP; Curve 2 for 100 kGy electron irradiated $\mathrm{ChP}$. 


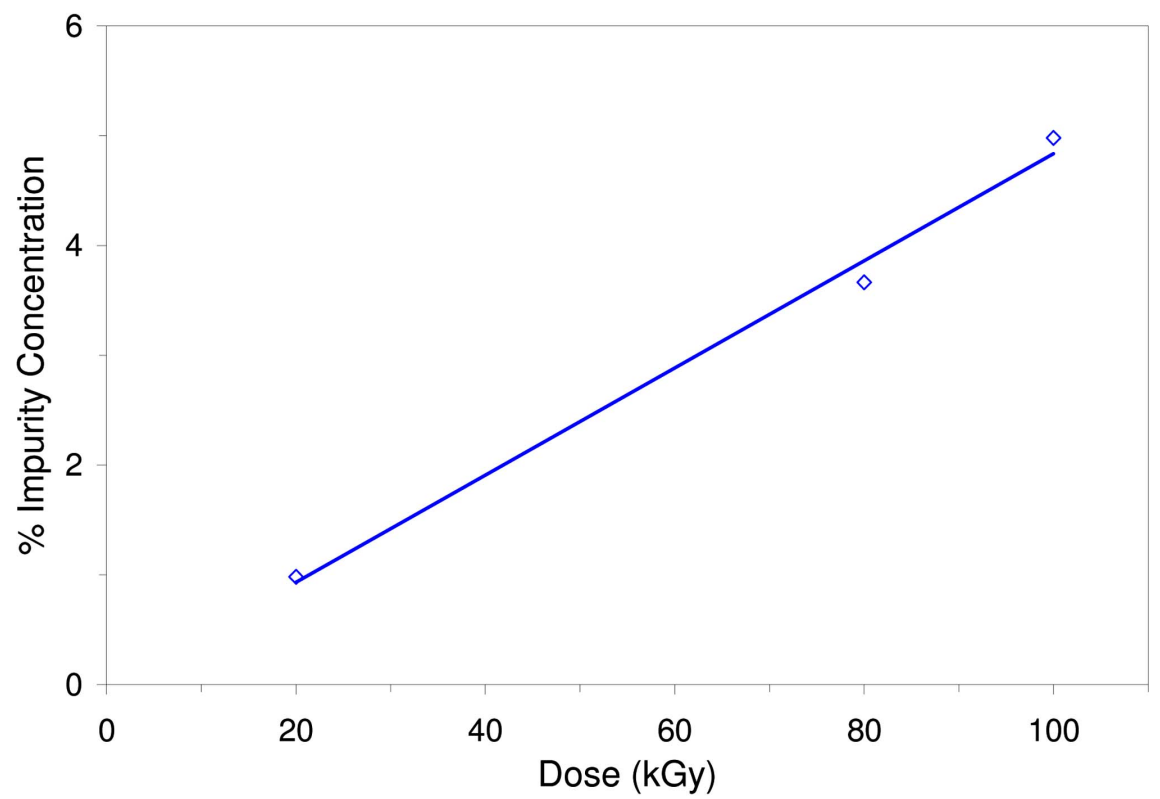

Fig. (7). Variation of the percentage impurity concentration (x) with irradiation dose (in kGy).

Therefore, it can be said that the irradiated sample becomes a bicomponent mixture after irradiation.

The Van't Hoff equation is widely used in calculating impurities in organic and inorganic materials [22, 23]. Liquid crystalline materials are organic materials and therefore this equation can be used to calculate the impurities produced due to electron beam irradiation. We have calculated the concentration of the impurities produced due to electronirradiation by using the Van't Hoff equation given by

$x=\frac{\Delta H \cdot \delta T}{R \cdot T_{0}^{2}}$

Eq. 1

Where $\mathrm{x}$ is the molar fraction of impurities, $\Delta H$ and $T_{0}$ are the enthalpy (in $\mathrm{Cal} / \mathrm{mol}$ ) and melting point (in $\mathrm{K}$ ) for the pure material and $\delta T$ is the depression in the melting temperature due to impurity. $\mathrm{R}(=1.987 \mathrm{Cal} / \mathrm{deg} . \mathrm{mol})$ is the universal gas constant. Using Eq. 1, we have estimated the percentage impurity concentration for irradiated samples. Fig. (7) shows the variation of the impurity concentrations with irradiation dose. This plot suggests that the concentration of impurity increases with the increasing dose of irradiation. The concentration of impurity for the $100 \mathrm{kGy}$ electron irradiated sample comes out to be $5 \%$ which is in agreement which those estimated by UV spectra $(6 \pm 2 \%)$.

\section{CONCLUSIONS}

Changes in the optical and thermodynamical properties of cholesteryl pelargonate $(\mathrm{ChP})$ due to electron beam irradiation are summarized as follows:

1. UV-Vis absorption spectra of the irradiated sample show a charge transfer complex peak at $289.2 \mathrm{~nm}$ (corresponding energy $4.30 \mathrm{eV}$ ) besides a peak of the pure sample at $252.0 \mathrm{~nm}$ (corresponding energy $4.93 \mathrm{eV}$ ). This suggests that the band gap of ChP decreases due to electron beam irradiation.

2. Transition temperatures are lowered due to irradiation as compared to those of the pure sample.
3. The depression in the transition temperature is linear with irradiation dose.

4. The temperature range of cholesteric $\left(\mathrm{N}^{*}\right)$ phase increases by $16 \%$ while that of the smectic A (SmA) phase increases marginally $(\sim 4 \%)$ due to irradiation.

5. Transition enthalpies $(\Delta \mathrm{H})$ and entropies $(\Delta \mathrm{S})$ are decreased due to irradiation.

6. The variations of the average transition enthalpies and entropies are found to be linear with the irradiation dose.

7. The impurities produced due to the irradiation also vary linearly with the irradiation dose.

\section{ACKNOWLEDGEMENT}

The work is financially supported under a DAE-BRNS project scheme. One of us RV thanks DAE-BRNS for a fellowship under the project. RV also thanks CSIR, New Delhi for his present fellowship under its CSIR-SRF scheme. Authors are also thankful to NCFRR, University of Pune (India) for providing irradiation facilities.

\section{REFERENCES}

[1] Pandey MB, Dhar R, Wadhawan VK. Phase transitions and recent advances in liquid-crystals research. Phase Transitions 2009; 82: 831 .

[2] Siedle AH, Len Adams. Handbook of Radiation Effects, 2nd edition, New York, USA: Oxford University Press 2002; p-61.

[3] Dhar R. Liquid Crystals: electrical, optical and thermodynamic properties, Thesis, University of Allahabad, Allahabad, 1996; p-173.

[4] Srivastava SL, Dhar R, Kurik MV. Change in electrical and thermodynamic properties of Cholesteryl Myristate on irradiation. Mol Mat 1993; 2: 261.

[5] Aliev DF, Lavrentovich OD, Linev BA, Mamedov NM. The influence of irradiation on threshold voltage for homeotropic to planar transition in smectic phase of Cholesteryl Pelargonate. Ukr J Phys 1987; 32 : 1220 (in Russian).

[6] Verma Rohit, Dhar R, Dabrowski R, et al. Electron Beam Irradiation Induced Transformations in the Electro-Optical and Dielectric Properties of A Twisted Nematic Display Material (5CB). J Phys D Appl Phys 2009; 42: 085503. 
[7] Verma Rohit, Dhar R, Agrawal VK, et al. Electron Beam Irradiation Induced Transformations In The Electrical Properties Of 4'Octyl-4-Cynobiphenyl (8CB). Liq Cryst 2009; 36: 1003.

[8] Verma Rohit, Dhar R, Rath MC, et al. Optimization Of The Display Parameters Of A Room Temperature Nematic Material (6CHBT) By Using Electron Beam Irradiation. J Disp Tech 2010; 6: 1 .

[9] Kleiman RN, Bishop DJ, Pindak R, Taborek P. Shear Modulus and Specific Heat of the Liquid-Crystal Blue Phases. Phys Rev Lett 1984; 53: 2137

[10] Thoen J. Adiabatic scanning calorimetric results for the blue phases of cholesteryl Nonanoate. Phys Rev A 1988; 37: 1754.

[11] Guha SN, Moorthy PN, Kishore K, Naik DB, Rao KN. Oneelectron reduction of thionine studied by pulse radiolysis. Proc Indian Acad Sci Chem Sci 1987; 99: 261.

[12] Srivastava AK, Agrawal VK, Dabrowski R, Oton JM, Dhar R. Electro-optical and dielectric relaxation studies of an antiferroelectric liquid-crystal mixture (W-132A). J Appl Phys 2005; 98: 013543.

[13] Gupta M, Dhar R, Agrawal VK, Dabrowski R, Tykarska M. Dielectric spectroscopy of a binary mixture of liquid crystals showing wide temperature range twisted grain boundary phase with re-entrant cholesteric phase. Phys Rev E 2005; 72: 021703-10.

[14] Kunihisa KS, Satomi Y. Phase transitions of cholesteryl acetylferulate. Mol Cryst Liq Cryst 1986; 141: 1.
[15] Srivastava SL, Agrawal VK. Dependence of thermodynamical parameters of mesophase transitions in a liquid crystal on scanning rate from DSC studies. Nat Acad Sci Letters 1990; 13: 243.

[16] Srivastava SL, Dhar R, Kurik MV. Change in electrical and thermodynamical properties of Cholesteryl Myristate on irradiation. Mol Mat 1993; 2: 261

[17] Alfassi ZB, Kushelevsky AP, Feldman L. The effect of $\gamma$ irradiation of solutions of cholesteric liquid crystals on the color transition temperature. Mol Cryst Liq Cryst 1977; 39: 33.

[18] Srivastava SL, Dhar R. Effect of $\Upsilon$-irradiation on liquid crystalline properties of Cholesteryl Pelargonate (Nonanoate). Radiat Phys Chem 1996; 47: 287.

[19] Srivastava SL, Suri SK, Gouda FM. Research Report, Department of Physics, Faculty of Science. University of Gar Younis, Benghazi Libya, New York, USA: John Wiley 1983.

[20] Pething R. Dielectric and electronic properties of biological materials, New York, USA: John Wiley 1979; p-323.

[21] Torrance JB. An Overview of organic charge-transfer solids: insulators, metals, and the neutral-ionic transition. Mol Cryst Liq Cryst 1985; 126: 55 .

[22] Ennulat RD, Porter RS, Johnson JF. Analytical calorimetry 1968; 229: 219.

[23] Barrall EM, Vogal MJ. The effect of purity on the thermodynamic properties of cholesteryl heptadecanoate. Thermochim Acta 1970; $1: 127$ 